\title{
Statistical Approach to Strength Degradation Analysis during Water Quenching
}

\author{
Hideo AWAJI, Sawao HONDA and Tadahiro NISHIKAWA \\ Department of Materials Science and Engineering, Nagoya Institute of Technology, Gokiso-cho, Showa-ku, Nagoya-shi 466-8555
}

\author{
水中急冷時の強度低下に関する統計的解析 \\ 淡路英夫・本多沢雄・西川直宏 \\ 名古屋工業大学材料工学科, 466-8555 名古屋市昭和区御器所町
}

\begin{abstract}
In many ceramics, stress corrosion cracking precedes fast fracture in an activated environment, and leads to degradation in strength during water quenching. The strength degradation during water-quench thermal shock testing, therefore, may be caused by both stress corrosion cracking and thermal shock cracking. In this study, the degree of strength degradation by water quenching is determined experimentally using alumina material, and the reduction behavior in strength is analyzed statistically and distinguished as stress corrosion cracking or thermal shock cracking. A new definition of the critical temperature difference in water-quench thermal shock testing is also proposed based on this statistical approach.
\end{abstract}

[Received November 10, 1997; Accepted March 30, 1998]

Key-words : Water quenching, Statistical approach, Thermal shock, Stress corrosion cracking, Critical temperature difference, Alumina

1. Introduction

The water quenching has been extensively employed in industry to characterize thermal shock properties in ceramics despite many questions remaining unanswered. ${ }^{1)}$ However, research into a standardization of the technique is in progress because of its simplicity. ${ }^{2)}$ The Japanese Industrial Standards JIS R $1615^{3)}$, established in 1993, provides a procedure for water quenching of ceramics. The JIS prescribes that the specimen configuration should be a circular cylinder, and that the probability of crack appearance on the specimen surface after quenching should be used to estimate the critical temperature difference as a parameter of thermal shock in ceramics.

A different technique, known as the 'Hasselman plot', ${ }^{4)}$ is also widely used. In this technique, a heated flexural specimen is quenched in cold water. Subsequent flexure testing of the quenched specimen provides the relation between strength degradation and temperature difference. The temperature difference at which a marked reduction in the retained strength occurs is then quoted as the thermal shock resistance.

In many ceramics, however, stress corrosion cracking precedes fast fracture in an activated environment, and leads to strength degradation during water quenching. Strength degradation during water-quench thermal shock testing, therefore, may be caused by the following two phenomena; stress corrosion cracking and thermal shock cracking. ${ }^{13)}$ The statistical nature of the retained strengths of the quenched specimens has been analyzed by Rogers et al.,5) although they did not examine stress corrosion cracking.

In this paper, the degree of the strength degradation due to water quenching is estimated experimentally using alumina material, and the reduction in the strength is analyzed by a statistical approach to distinguish the effects of the stress corrosion cracking from those of thermal shock cracking. A new definition of the critical temperature difference, $\Delta T_{c}$, in water quenching is also proposed.

2.1 Specimen

\section{Experiments}

The ceramic material used was $99.5 \%$ purity alumina
(Mitsui Mining Co., Ltd.). Specimens of dimensions $3 \times 4 \times 40 \mathrm{~mm}$ were machined out, and the $3 \times 40 \mathrm{~mm}$ surface of the specimen was chamfered and finished by carefully polishing with diamond paste. The physical properties of the material are shown in Table 1. The bulk density was measured by means of an Archimedes' method, and Young's modulus and the Poisson's ratio by means of an ultrasonic pulse method. Other properties were assumed from the catalogue.

2.2 Test of initial inert strength

The strength of the alumina before quenching was measured using a four-point flexure test with the inner and outer spans 10 and $30 \mathrm{~mm}$, respectively; in accordance with the JIS R 1601 standard.6) The width and height of each specimen selected were 3 and $4 \mathrm{~mm}$, respectively, and the cross head speed was $0.1 \mathrm{~mm} / \mathrm{min}$. Ten specimens were prepared for this test. The polished specimens were dried in oven at $120^{\circ} \mathrm{C}$ for one day and then tested under a dried $\mathrm{N}_{2}$ gas atmosphere. The equipment used for the flexure test is shown in Fig. 1. The measured strength using this technique we have called the 'initial inert strength' in this paper.

\subsection{Water quenching test}

As shown in Fig. 2, after polishing and drying, the specimens were pasted together with spacers of alumina to ensure one-dimensional thermal transfer across the width of the specimen.7) A water guide made of a machinable ceramics was attached to the base of the specimen set to avoid entrapment of atmospheric gas in the cooling water during the quench. ${ }^{8}$ )

The water quenching equipment is shown in Fig. 3. This equipment consists of an electric furnace for heating the

Table 1. Physical Properties of the Specimen at Room Temperature

\begin{tabular}{cccccc}
\hline $\begin{array}{c}\text { Bulk } \\
\text { Density }\end{array}$ & $\begin{array}{c}\text { Young's } \\
\text { Modulus }\end{array}$ & $\begin{array}{c}\text { Poisson's } \\
\text { ratio }\end{array}$ & $\begin{array}{c}\text { Thermal } \\
\text { Conductivity }\end{array}$ & $\begin{array}{c}\text { Thermal } \\
\text { Diffusivity }\end{array}$ & $\begin{array}{c}\text { Coeff. Linear } \\
\text { thermal } \\
\text { expansion } \\
\rho / 10^{3} \mathrm{kgm}^{-3}\end{array}$ \\
$E / \mathrm{GPa}$ & $v /-$ & $\lambda / \mathrm{Wm}^{-1} \mathrm{~K}^{-1}$ & $\kappa / 10^{-6} \mathrm{~m}^{2} \mathrm{~s}^{-1}$ & $\alpha / 10^{-6} \mathrm{~K}^{-1}$ \\
\hline 3.90 & 380 & 0.24 & 29.8 & 9.35 & 8.0 \\
\hline
\end{tabular}




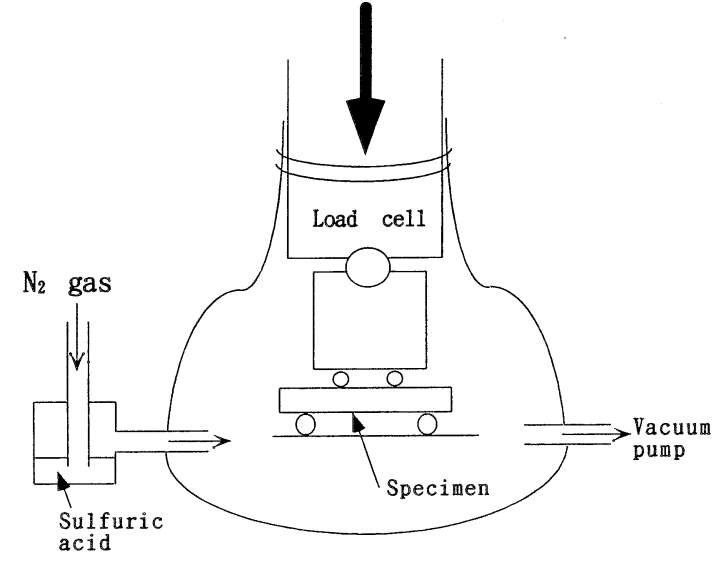

Fig. 1. Experimental equipment for flexure test in inert environment.

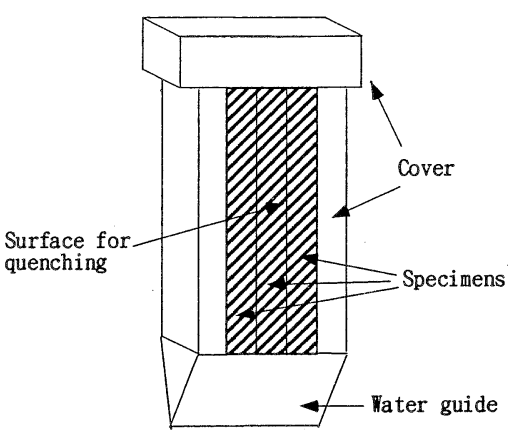

Fig. 2. A specimen set for water quenching.

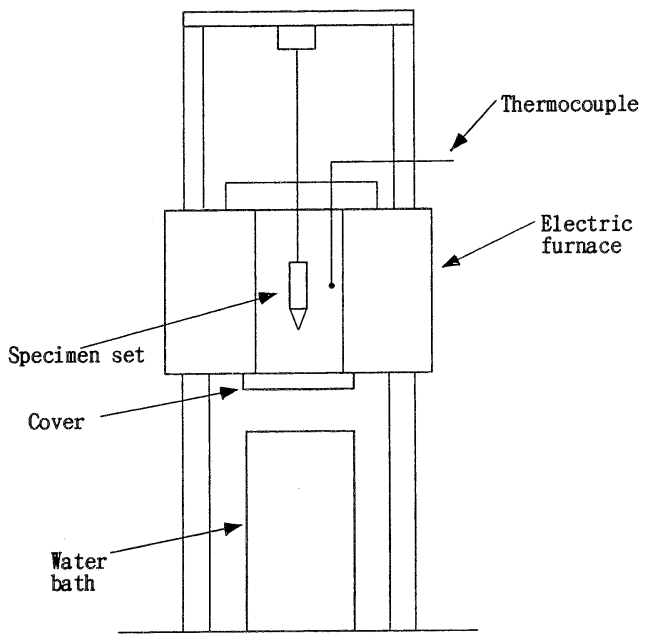

Fig. 3. Equipment for water quenching.

specimens and a water bath for quenching. Each set of specimens was initially heated to $225^{\circ} \mathrm{C}$ at a rate of $10^{\circ} \mathrm{C} / \mathrm{min}$, and maintained at this temperature for $30 \mathrm{~min}$ in the furnace, before being dropped into the water bath. The temperature of the water bath was maintained at $10^{\circ} \mathrm{C}$ during the test. The distance from the tip of the specimen set to the surface of the water before and after dropping was $0.6 \mathrm{~m}$. Variation in the heat transfer coefficient between the specimens and water during the quenching was considered to be small as the temperature difference at the surface of the specimen was only $215^{\circ} \mathrm{C}$ in this test, although the specimens probably were cooled by convection heat transfer. ${ }^{9)}$

\subsection{Test of retained strength}

After water quenching, cracks generated on a specimen's surface were examined with a dye-penetration technique. Each specimen was then dried in an oven again, and the four-point flexure test was carried out. The test was performed in a dried $\mathrm{N}_{2}$ gas environment to prevent stress corrosion cracking during the test. Of the twenty specimens quenched, cracks could be visually detected after dyepenetration on the surface of seven of them.

\section{Results and analysis}

3.1 Initial inert strength

The initial inert strength of alumina was mapped to the following 2-parameter Weibull distribution:

$$
F\left(S_{\mathrm{i}}\right)=1-\exp \left[-\left(\frac{S_{\mathrm{i}}}{S_{\mathrm{c}}}\right)^{m}\right]
$$

where $F\left(S_{\mathrm{i}}\right)$ is the failure probability distribution of the in itial inert strength of the specimen before quenching estimated in an inert atmosphere, $S_{i}$ is the initial inert strength, $m$ is the shape parameter and $S_{c}$ is the scale parameter. The Weibull plot for the initial inert strength is shown in Fig. 4. The cumulative failure probability was estimated by using a median-rank method, and the shape parameter and the scale parameter were calculated by means of a least-square approximation. The results indicate that the shape parameter, $m$, is 12.9 , and that the scale parameter, $S_{c}$, is $397 \mathrm{MPa}$. Figure 4 shows that the data are in good agreement with the 2-parameter Weibull distribution.

3.2 Original distribution of retained strength

After quenching, some specimens had visible cracks on their surfaces while others did not. Those specimens in which cracks appeared during the thermal shock had a significantly lower retained strength than those with no cracks. Thus, the strength distribution of the quenched specimens was widely spread, particularly among the lower strengths. The original strength distribution of the quenched specimens, therefore, must be estimated from the retained strength distribution for the specimens without thermal shock cracks. The relationships among the distribution functions of the initial inert strength, the actual apparent distribution of retained strength and the original distribution of retained strength are shown schematically in Fig. 5.

A statistical technique used to estimate the original

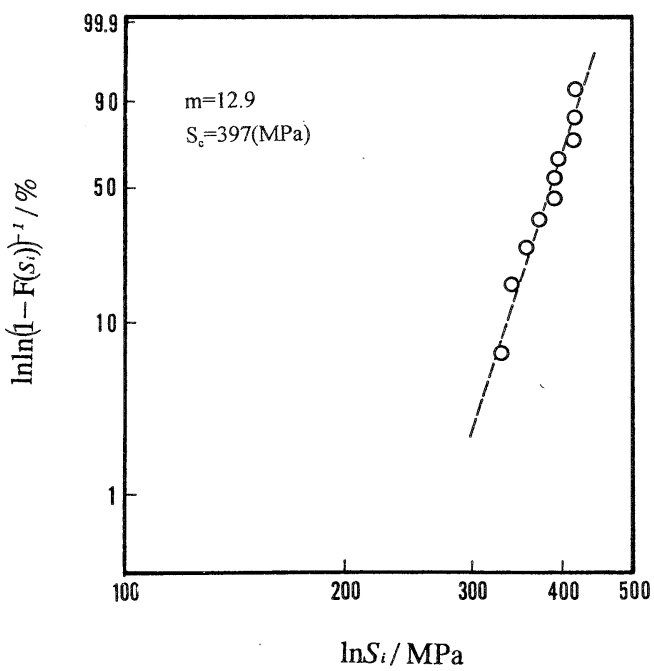

Fig. 4. Weibull plot for the initial inert strength of alumina. 


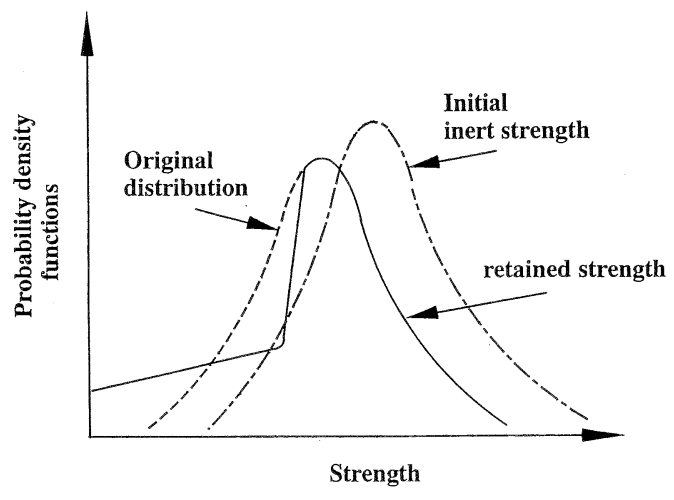

Fig. 5. Schematic relation of the three probability density functions, distribution of initial inert strengths, apparent distribution of retained strengths, and original distribution of retained strength.

strength distribution of the quenched specimens is as follows. ${ }^{10)}$ If the number of specimens quenched is $n$, of which those without surface cracks after quenching is equal to $k$, then the number of quenched specimens with surface cracks is $(n-k)$. First, the specimens without surface cracks are arranged in ascending order of retained strength. Then, a number for the ascending order of the strength is assigned such that the first specimen in the ascending order of strength becomes $(n-k+1)$-th, and $i$-th specimen becomes the $(n-k+i)$-th. The technique means that the original distribution will include the strengths of the specimens damaged during water quenching. The original strengths of the damaged specimens are unknown and only the number of the specimens is known. It is, however, enough to predict parameters for the Weibull distribution by a least-squared approximation from the known strengths of the number $k$.

Figure 6 shows the Weibull plot for all the data relating to the strength of the quenched specimens. The open circles indicate the retained strength of the specimens without thermal shock cracks, and the solid circles the retained strength of the specimens with thermal shock cracks that were visually detectable. The solid line in the figure represents the original distribution of retained strength as is calculated using the above mentioned technique. The distribution is expressed as follows:

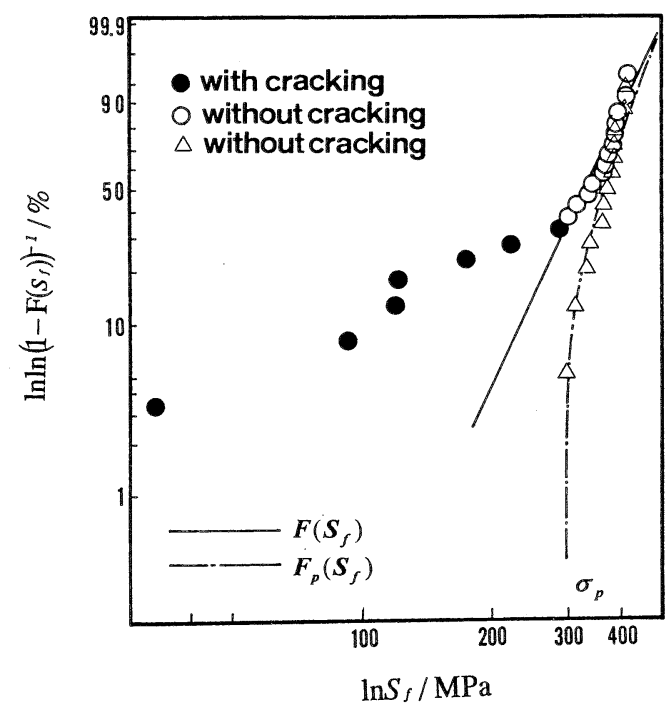

Fig. 6. Weibull plot for the retained strength of the quenched specimen.

$$
F\left(S_{\mathrm{f}}\right)=1-\exp \left[-\left(\frac{S_{\mathrm{f}}}{S_{\mathrm{fc}}}\right)^{m_{\mathrm{c}}}\right]
$$

where $F\left(S_{\mathrm{f}}\right)$ is the original distribution of the retained strengths of the quenched specimens, $S_{\mathrm{f}}$ is the retained strength, $m_{\mathrm{c}}$ is the shape parameter of the original distribution, and $S_{\mathrm{fc}}$ is the scale parameter of the original distribution. Curve fitting by least square method produces a shape parameter of 5.6 , and a scale parameter of $353 \mathrm{MPa}$. In Fig. 6, the retained strength of the specimens without thermal shock cracking is also plotted as represented by the open triangles $(\triangle)$. The truncated distribution which is similar to the strength distribution of proof-tested specimens, ${ }^{11)}$ is expressed as follows, ${ }^{7)}$

$$
F_{\mathrm{p}}\left(S_{\mathrm{f}}\right)=\frac{F\left(S_{\mathrm{f}}\right)-F\left(\sigma_{\mathrm{p}}\right)}{1-F\left(\sigma_{\mathrm{p}}\right)}
$$

where $\sigma_{\mathrm{p}}$ is the critical stress for thermal shock cracking, $F$ $\left(\sigma_{\mathrm{p}}\right)$ : percent point at $\sigma_{\mathrm{p}}$ of the original distribution of the retained strength, and $F_{\mathrm{p}}\left(S_{\mathrm{f}}\right)$ : the distribution of retained strength of the specimen without thermal shock cracks. Equation (3) is also depicted in Fig. 6 by a dot-dash-line.

Figure 7 compares the two distributions of the initial inert strength and the original retained strength. The strength degradation after water quenching can be clearly recognized. It is therefore supposed that stress corrosion cracking caused by thermal stress while quenching in cold water can lead to strength degradation. ${ }^{13}$ ) It is also evident that specimens of higher strength degrade relatively little, while those of lower strength exhibit a large reductions. The original retained strength distribution, therefore, shows lower strength than the initial inert strength as a whole, and may have a smaller value for the shape parameter.

Figure 8 shows the schematic relationship among the initial inert strength, $S_{\mathrm{i}}$, the retained strength after quenching, $S_{\mathrm{f}}$, and the thermal stress on the specimen during quenching. The strength degradations of the specimens with three different initial inert strengths, such as $S_{\mathrm{i} 1}>S_{\mathrm{i} 2}>$ $S_{\mathrm{i} 3}$, are illustrated in the figure, and the resulting thermal stress in the specimens is also illustrated. Actually, the thermal stresses introduced by water quenching increase quite rapidly, reaching a maximum value, $\sigma_{\max }$, at point $\mathrm{A}$ before decreasing. The specimen with an initial strength, $S_{\mathrm{i} 2}$, represents the case without thermal shock cracks, and thus indicates strength reduction only caused by stress corrosion

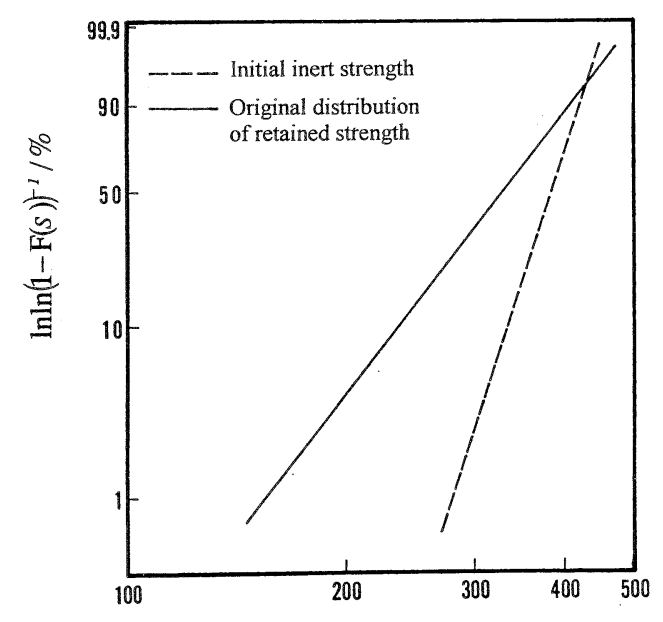

$\ln S / \mathrm{MPa}$

Fig. 7. Comparison of the distributions of the initial inert strength and the original retained strength. 


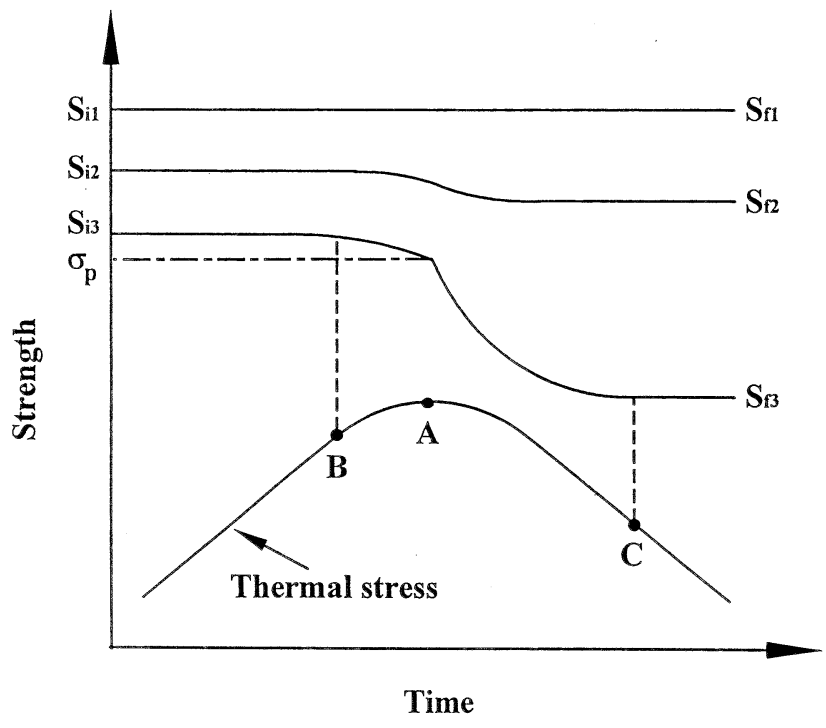

Fig. 8. Schematical relationship between the initial inert strength, the retained strength after quenching and the thermal stress.

cracking. In the specimen with an initial inert strength, $S_{\mathrm{i} 3}$ strength degradation occurs from point $B$ due to stress corrosion cracking, and thermal shock cracking in the specimen extend this remarkably as the thermal stresses in the specimen exceed the critical stress, $\sigma_{\mathrm{p}}$, but the crack extension will stop at the point $\mathrm{C}$. As a result, the retained strength becomes $S_{\mathrm{f} 3}$, and the specimen has thermal shock cracks.

A reasonable technique for estimating the critical temperature difference in water quenching is proposed here using the failure probability distributions of original retained strength. The critical temperature difference, which is a measure of thermal shock resistance, $\Delta T_{\mathrm{c}}$, is defined using the temperature difference at which a specimen with mean strength corresponding to the original strength distribution would be damaged by water quenching.

It is assumed that there is no temperature dependence on the material properties ${ }^{12)}$ in the following discussion for simplicity. The maximum value of the non-dimensional thermal stress in a quenched plate is expressed using the Biot number, $\beta$, as follows:

$$
\frac{1}{\sigma_{\max }^{*}}=1.5+\frac{3.25}{\beta}
$$

where $\beta=h l / \lambda, h$ is the heat transfer coefficient, $l$ is the plate thickness, and $\lambda$ is the thermal conductivity, and the non-dimensional stress, $\sigma_{\max }^{*}$, is defined as:

$$
\sigma_{\max }^{*}=\frac{\sigma_{\max }}{E \alpha \Delta T}
$$

where $\sigma_{\max }$ is the maximum thermal stress in a specimen, $E$ is Young's modulus, $\alpha$ is the coefficient of linear thermal expansion, and $\Delta T$ is the temperature difference suffered.

The mean strength is estimated from the following equation, ${ }^{11)}$ assuming a 2-parameter Weibull distribution,

$$
\bar{S}=S_{\mathrm{c}} \Gamma\left(1+\frac{1}{m}\right)
$$

where $\Gamma$ is a gamma function, and $\bar{S}$ is the mean strength of the distribution function with Weibull parameters $m$ and $S_{\text {c }}$.

If we assume that $\beta$ in Eq. (4) is independent of the temperature difference near the critical temperature difference considered, then, the following equation can be derived from Eqs. (4) and (5).

$$
\frac{\Delta T_{\mathrm{c}}}{S}=\frac{1}{E \alpha}\left(1.5+\frac{3.25}{\beta}\right)=\text { const. }
$$

Therefore, when water quenching with a temperature difference, $\Delta T_{x \%}$, yields thermal shock cracks in $x$ percent specimens, and $S_{\mathrm{i}(F=x \%)}$ is the $x$ percent point in the original distribution of retained strength, the following relationship can be derived, assuming that the mean strength is almost equal to the median strength.

$$
\frac{\Delta T_{\mathrm{c}}}{S}=\frac{\Delta T_{x \%}}{S_{\mathrm{i}(F=x \%)}}
$$

In this experiment, the quenching test was performed with a temperature difference $\Delta T_{x \%}=215^{\circ} \mathrm{C}$ and $x=35 \%$ of the specimens had thermal shock cracks. The $35 \%$ point of the original distribution of retained strength is then calculated from Eq. (2) as $304 \mathrm{MPa}$. The mean strength of the original distribution is estimated by Eq. (6) as 326 $\mathrm{MPa}$. These values yield a critical temperature difference of $231^{\circ} \mathrm{C}$ from Eq. (8).

\section{Conclusions}

Strength degradation through water quenching in alumina was ascertained experimentally with the reduction in strength caused by stress corrosion cracking and thermal shock cracking separately analyzed by a statistical approach. The statistical estimation of the critical temperature difference in water quenching was also shown using the original distributions of retained strength for specimens without thermal shock cracks.

\section{References}

1) H. Awaji, S. Honda and T. Nishikawa, JSME Int. J., 40, 41422 (1997).

2) R. Morrell, "Thermal Shock and Thermal Fatigue Behavior of Advanced Ceramics," Ed. by G. A. Schneider and G. Petzow, NATO ASI Ser. E, Kluwer Academic Publ. Dordrecht, The Netherlands (1993) pp. 27-32.

3) JIS R 1615 (1993)

4) W. E. Pompe, "Thermal Shock and Thermal Fatigue Behavior of Advanced Ceramics," Ed. by G. A. Schneider and G. Petzow, NATO ASI Ser. E, Kluwer Academic Publ. Dordrecht, The Netherlands (1993) pp. 3-14.

5) W. P. Rogers, A. F. Emery, R. C. Bradt and A. S. Kobayashi, J. Am. Ceram. Soc., 70, 406-12 (1987)

6) JIS R 1601 (1981).

7) H. A. Bahr, G. Fisher and H. J. Weiss, J. Mater. Sci., 21, 2716-20 (1986).

8) T. Sakuma, U. Iwata and H. Takaku, Trans. JSME, 57A, 2741-46 (1991).

9) T. Gao, T. Nishikawa, M. Hibi and M. Takatsu, J. Ceram. Soc. Japan, 101, 788-92 (1993).

10) Y. Sakaida, H. Awaji and M. Ichikawa, Trans. JSME, 58A, 936-42 (1992).

11) M. Ichikawa, "Kouzou-Sinrai-Sei Kougaku," Kaibundo (1988).

12) S. Honda, T. Takahashi, S. Morooka, S. Zhang, T. Nishikawa and H. Awaji, J. Soc. Mater. Sci. Jpn., 46, 1300-05 (1997).

13) Y. Mutoh and S. Arakawa, "Fracture Mechanics of Ceramics Vol. 11," Ed. by R. C. Bradt, D. P. H. Hasselman, D. Munz, M. Sakai and V. Ya. Shevchenko, Plenum Press, New York (1996) pp. 495-506. 